\title{
Exhaustive expansion: A novel technique for analyzing complex data generated by higher- order polychromatic flow cytometry experiments
}

\author{
Janet C Siebert ${ }^{1}$, Lian Wang ${ }^{2}$, Daniel P Haley ${ }^{3}$, Ann Romer ${ }^{2}$, Bo Zheng ${ }^{2}$, Wes Munsil ${ }^{1}$, Kenton W Gregory ${ }^{2}$, \\ Edwin B Walker ${ }^{3}$
}

\begin{abstract}
Background: The complex data sets generated by higher-order polychromatic flow cytometry experiments are a challenge to analyze. Here we describe Exhaustive Expansion, a data analysis approach for deriving hundreds to thousands of cell phenotypes from raw data, and for interrogating these phenotypes to identify populations of biological interest given the experimental context.

Methods: We apply this approach to two studies, illustrating its broad applicability. The first examines the longitudinal changes in circulating human memory $T$ cell populations within individual patients in response to a melanoma peptide (gp100 209-2M) cancer vaccine, using 5 monoclonal antibodies (mAbs) to delineate subpopulations of viable, gp100-specific, CD8+ T cells. The second study measures the mobilization of stem cells in porcine bone marrow that may be associated with wound healing, and uses 5 different staining panels consisting of 8 mAbs each.
\end{abstract}

Results: In the first study, our analysis suggests that the cell surface markers CD45RA, CD27 and CD28, commonly used in historical lower order (2-4 color) flow cytometry analysis to distinguish memory from naïve and effector T cells, may not be obligate parameters in defining central memory T cells $\left(T_{C M}\right)$. In the second study, we identify novel phenotypes such as CD29+CD31+CD56+CXCR4+CD90+Sca1-CD44+, which may characterize progenitor cells that are significantly increased in wounded animals as compared to controls.

Conclusions: Taken together, these results demonstrate that Exhaustive Expansion supports thorough interrogation of complex higher-order flow cytometry data sets and aids in the identification of potentially clinically relevant findings.

\section{Background}

Flow cytometry (FCM) is a powerful technology with major scientific and public health relevance. FCM can be used to collect multiple simultaneous light scatter and antigen specific fluorescence measurements on cells as each cell is excited by multiple lasers and emitted fluorescence signals are passed along an array of detectors. This technology permits characterization of various cell subpopulations in complex mixtures of cells. Using new higher-order multiparameter FCM techniques we can simultaneously identify $\mathrm{T}$ and $\mathrm{B}$ cell subsets, stem

\footnotetext{
* Correspondence: jsiebert@cytoanalytics.com

${ }^{1}$ CytoAnalytics, Denver, CO, USA Full list of author information is available at the end of the article
}

cells, and specific cell surface antigens, cytokines, chemokines, and phosphorylated proteins produced by these cells. Higher order FCM allows us to measure at least 17 parameters per cell [1], at rates as high as 20,000-50,000 cells per second.

Increasing sophistication in FCM, coupled with the inherent complex dimensionality of clinical and translational experiments, leads to data analysis bottlenecks. While the literature documents a long history of automated approaches to gating events within a single sample [2-4], the gated data remains complex, with readouts for tens to hundreds of phenotypes per sample, multiple samples per patient, and multiple cohorts per study. Unfortunately, there is a paucity of proven analytical
Ciomed Central 
approaches that provide meaningful biological insight in the face of such complex data sets.

Furthermore, interpretation of results from higher order experiments may be biased by historical results from simpler lower order experiments. Marincola [5] suggests that modern high-throughput tools, coupled with high-throughput analysis, provide a more unbiased opportunity to reevaluate the basis of human disease, while advocates of cytomics [6,7] observe that exhaustive bioinformatics data extraction avoids the inadvertent loss of information associated with a priori hypotheses. Fundamentally, these authors underscore the distinction between inductive (hypothesis-generating) and deductive (hypothesis-driven) reasoning. This distinction is clearly applicable to the interpretation of higher-order multiparameter flow cytometry data. Herein, we apply a powerful inductive data analysis approach to two distinctly different studies in order to demonstrate its broad applicability. The first study examines human memory $\mathrm{T}$ cell responses to a melanoma peptide cancer vaccine, while the second inspects porcine stem cell phenotypes associated with wound healing.

In a previously described melanoma booster vaccine study [8], we used 8-color FCM to characterize the phenotypes of viable $\left(7 \mathrm{AAD}^{-}\right)$melanoma antigen-specific (gp100 tetramer $\left.{ }^{+}\right) \mathrm{CD}^{+} \mathrm{T}$ cells collected from peripheral blood. Memory and effector $\mathrm{T}$ cell subpopulations responding to vaccine antigen were characterized using 5 additional monoclonal antibodies (mAbs) specific for CCR7, CD45RA, CD57, CD27, and CD28. Samples were collected from 7 donors at 3 time points: after (post) the initial vaccine regimen (PIVR); at a long term memory (LTM) time point collected 18 to 24 months after the end of vaccine administration; and after two boosting vaccines (P2B). Phenotypes for $\mathrm{T}_{\mathrm{CM}}$ have been described based on lower-order 3-4 color staining with different combinations of the above antibodies, with data suggesting a consensus $\mathrm{T}_{\mathrm{CM}}$ phenotype of CCR7 +CD45RA-CD57-CD27+CD28+. We demonstrated that LTM gp100-specific CD8 ${ }^{+} \mathrm{T}$ cells were enriched for this consensus phenotype [8]. We also described a gp100specific $\mathrm{T}_{\mathrm{CM}}$ subset that retained CD45RA expression (CCR7+CD45RA+CD57-CD27+CD28+), which we termed $\mathrm{T}_{\mathrm{CMRA}}$, and which may represent a $\mathrm{T}_{\mathrm{CM}}$ precursor population similar to that described in the mouse [9]. Although this consensus phenotype has previously been used to primarily define naïve $T$ cells, it clearly characterized a subpopulation of antigen-educated (i.e. gp100 tetramer positive) long term memory CD8 ${ }^{+}$ $\mathrm{T}$ cells in the melanoma vaccine study. This phenotype signature may delineate a $\mathrm{T}_{\mathrm{CM}}$ precursor population that arises shortly after antigen activation of naïve $\mathrm{T}$ cells. Thus, studies in the mouse demonstrate that tumor-specific $\mathrm{T}_{\mathrm{CM}}$ and similar putative $\mathrm{T}_{\mathrm{CM}}$ precursors, referred to as central memory stem cells $\left(\mathrm{T}_{\mathrm{SCM}}\right)$, which may derive from early daughter cell division after antigen stimulation of naïve $\mathrm{T}$ cells, express elevated levels of proliferation, enhanced survival in vivo, and superior CTL function compared to effector or effector-memory $\left(\mathrm{T}_{\mathrm{EM}}\right) \mathrm{T}$ cells [9]. However, the origin of $\mathrm{T}_{\mathrm{CM}}$ and $\mathrm{T}_{\mathrm{SCM}}$ precursors remains controversial, since other data supports the hypotheses that such memory subpopulations may also develop from effector and effector-memory $\mathrm{T}$ cells [10]. Controversy aside, enhanced proliferative and survival properties characteristic of memory $\mathrm{T}$ cells have been correlated with antitumor responses in mice and humans receiving adoptive $\mathrm{T}$ cell-based therapies [11]. Thus, the use of higherorder flow cytometry and comprehensive multiparameter data analysis could facilitate the identification and expansion of $\mathrm{T}_{\mathrm{CM}}$ and $\mathrm{T}_{\mathrm{CM}}$ precursor subpopulations (i.e. $\mathrm{T}_{\mathrm{SCM}}$ ) for more effective cancer immunotherapy regimens. However, such a therapeutic strategy would depend on first demonstrating memory $\mathrm{T}$ cell functional properties by sorted cells exhibiting such putative memory phenotype signatures.

Our second study examines complex stem cell phenotypes mobilized in response to wound healing. One use of stem cell therapy may be that of repairing damaged tissues, since bone marrow stem and progenitor cells can differentiate into muscle cells, endothelial cells, and nerve cells in vitro and in vivo [12]. Extremity injuries complicated by compartment syndrome (e.g. traumarelated severe swelling that can lead to ischemia and permanent tissue necrosis) are a common consequence of battlefield trauma, crush injuries that have been reported in recent earthquakes, and many sport injuries. While faciotomy can reduce the injury, there is no treatment that replaces or regenerates muscle and nerve tissues, leaving the patient with a permanent disability [13]. Human studies have demonstrated that injection of bone marrow stem cells into ischemic muscle may reduce the damage to the muscle and the loss of muscle function [14-18]. We have hypothesized that healthy, autologous bone marrow stem cells could be used to treat compartment syndrome. Our initial investigation focused on determining the optimal time to harvest bone marrow stem and progenitor cells after injury in the event that injury might amplify the mobilization of stem cell populations in the bone marrow. Bone marrow samples were collected from 8 injured swine and 8 control swine at pre-injury (baseline) and at 4 consecutive one-week intervals. Bone marrow was characterized by 5 different staining panels consisting of $8 \mathrm{mAbs}$ each, as presented in Table 1. In total, 12 different monoclonal antibodies (CD29, ckit, CD56, CXCR4, CD105, CD90, Sca-1, CD44, CD31, CD144, CD146, and VEGFR2) were used. Others have used more restrictive lower order 
Table 1 Five monoclonal antibody panels for stem cell study

\begin{tabular}{rlllll}
\hline \multicolumn{1}{c}{ Panel } & Main & CD31 & CD144 & CD146 & VEGFR2 \\
\hline Antibody & CD29 & CD29 & CD29 & (CD146) & CD29 \\
\hline ckit & (CD31) & (CD144) & ckit & ckit \\
\hline CD56 & CD56 & CD56 & CD56 & CD56 \\
\hline CXCR4 & CXCR4 & CXCR4 & CXCR4 & CXCR4 \\
\hline CD105 & CD105 & CD105 & CD105 & CD105 \\
\hline CD90 & CD90 & CD90 & CD90 & (VEGFR2) \\
\hline Sca-1 & Sca-1 & Sca-1 & Sca-1 & Sca-1 \\
\hline CD44 & CD44 & CD44 & CD44 & CD44
\end{tabular}

Each of the 5 panels consists of $8 \mathrm{mAbs}$. The differences from the main panel are indicated both in the name of the panel and by the antibody listed in parentheses.

combinations of these markers to delineate mesenchymal stem cells (CD29, CD90, and CD44) [19,20], primitive stem cells (ckit, CXCR4, and Sca-1) [21-23], myoblasts (CD56 and CXCR4) [24,25], and vascularrelative cells (CD146, CD31, CD144, CD105, and VEGFR2) [26-29]. However, to date, there has been no description of the combined use of all of these putative progenitor cell set descriptors in higher order staining panels.

Our multiparameter studies allow the identification of hundreds to thousands of phenotypes of cells, based on combinations of positive or negative expression of the included mAbs. For example, in the melanoma vaccine study, we initially considered all $32\left(2^{5}\right)$ possible phenotypes defined by positive and negative combinations of all 5 variable markers, e.g. CCR7+CD45-CD57-CD27 $+\mathrm{CD} 28+[8]$. This type of analytical strategy is used by many researchers [30-32]. However, it focuses on populations defined by exactly the number of variable parameters in the staining panel $(5$, in the case of the vaccine study). Thus, to more thoroughly explore the data, we exhaustively expanded the data sets to include all possible phenotypes defined by combinations of 0,1 , 2, 3, 4, and 5 markers, e.g. CCR7+ and CCR7+CD57$\mathrm{CD} 27+\mathrm{CD} 28+$. When each marker can assume one of two values (positive or negative), the number of possible cell subsets in an $\mathrm{M}$-marker study is $2^{\mathrm{M}}$. When each marker can assume one of three possible values (positive, negative, or unspecified), the number of possible cell sets is $3^{\mathrm{M}}$, or $3^{5}(243)$ in this 5 marker study, as illustrated in Table 2. In the wound healing study, bone marrow was characterized by 5 different 8 color panels. Exhaustive Expansion of these 8 marker sets to include all possible $0,1,2, \ldots 8$ marker sets resulted in $6,561\left(3^{8}\right)$ sets per panel, for a total of 32,805 $(6,561 \times 5$ panels $)$ cell subpopulations per sample.

Since we could not manually analyze data from hundreds to thousands of phenotypes efficiently, we first identified numerically interesting phenotypes by computing metrics for all derived sets. For example, in the melanoma vaccine study, the middle of three time points represented a long term memory time point, collected 18 to 24 months after exposure to the vaccine antigen. Consequently, one feature of interest was the delineation of phenotypes that peaked at this long term memory time point. In the wound healing study, since there were both wounded animals and control animals, we could identify phenotypes in which the expression levels for the wounded animals were greater than the levels for the control animals. In each case, simple visualizations, such as those presented in the Results, illustrated the patterns of response and helped us vet the numerically interesting phenotypes for biological relevance. In both studies we identified results with possible important clinical implications that would have been very difficult to find using standard analytical techniques. Using Exhaustive Expansion we were able to define a putative minimum obligate phenotype for central memory $\mathrm{T}$ cells, and delineate multiple bone-marrow-derived putative myogenic MSC subpopulations that may be mobilized in response to myonecrotic injury.

\section{Methods}

\section{Melanoma Vaccine Study}

The clinical trial protocol and the flow cytometry staining and analysis procedures used to acquire data in this study have been described in detail elsewhere $[8,33]$. Briefly, early stage melanoma patients were vaccinated every second or every third week over six months with a modified, HLA-A2 restricted melanoma associated peptide, gp $100_{209-2 \mathrm{M}}$. Leukophereses were collected before the vaccine regimen, after (post) the initial vaccine regimen (PIVR); at a long term memory (LTM) time point 18-24 months later; and following two additional boosting vaccines (P2B) given at one month intervals following the LTM leukopak collection. The protocol was reviewed by NCI's CTEP and approved by the Providence Health System institutional review board. All patients gave written informed consent. Cryopreserved PBMCs from PIVR, LTM and P2B time points were stained simultaneously with gp100 tetramers and with mAbs specific for CD8 $\beta$, CCR7, CD45RA, CD57, CD27, CD28, and with 7AAD to discriminate live from dead cells. All samples were analyzed on a 9 color Beckman Cyan ADP flow cytometer. Viable lymphocytes were gated for positive CD8 $\beta$ and gp100 tetramer staining, and gp100-specific CD $8 \beta^{+} \mathrm{T}$ cells were further interrogated for expression of the remaining five cell surface markers (CCR7, CD45RA, CD57, CD27, and CD28) to determine their subphenotypes. At least 5,000 gp100-specific CD8 $\beta^{+} \mathrm{T}$ cells were collected per sample. 
Table 2 Combinations of positive/negative phenotypes in a 5-marker panel

\begin{tabular}{|c|c|c|c|c|}
\hline $\begin{array}{l}\text { Number of } \\
\text { markers } \\
\text { (M) }\end{array}$ & $\begin{array}{l}\text { Number of }+/ \text { - gates } \\
\text { given } M \text { markers } \\
\text { (G) }\end{array}$ & Combinations & $\begin{array}{r}\text { Number of combinations of } M \text { markers } \\
\text { in a } 5 \text { marker panel (C) }\end{array}$ & $\begin{array}{r}\text { Number of gates } \\
\text { times number } \\
\text { of combinations } \\
(G \times C)\end{array}$ \\
\hline 0 & $2^{0}=1$ & No markers specified & 1 & 1 \\
\hline 1 & $2^{1}=2$ & $A, B, C, D, E$ & 5 & 10 \\
\hline 2 & $2^{2}=4$ & $\begin{array}{l}A B, A C, A D, A E, B C, B D, B E, C D \\
C E, D E\end{array}$ & 10 & 40 \\
\hline 3 & $2^{3}=8$ & $\begin{array}{l}A B C, A B D, A B E, A C D, A C E, A D E \\
B C D, B C E, B D E, C D E\end{array}$ & 10 & 80 \\
\hline 4 & $2^{4}=16$ & $A B C D, A B C E, A B D E, A C D E, B C D E$ & 5 & 80 \\
\hline 5 & $2^{5}=32$ & $\mathrm{ABCDE}$ & 1 & 32 \\
\hline
\end{tabular}

This table illustrates the total number of positive/negative gates in a 5-marker panel, with hypothetical markers A, B, C, D and E. There are five possible 1-marker combinations, ten 2-marker combinations, ten 3-marker combinations, five 4-marker combinations, and one 5-marker combination. For each combination, there are $2^{\mathrm{M}}$ positive/negative gates where $\mathrm{M}$ is the number of markers in the combinations. Thus, there are 243 possible phenotypes in a 5 marker experiment. This generalizes to $3^{\mathrm{M}}$.

All data was acquired in FCS format (Summit 4.2) and analyzed using the FCOM format of Winlist 5.0 Software (Verity House Software). "Fluorescence minus one" (FMO) controls were used to define positive and negative histogram staining regions for each fluorescent variable.

\section{Porcine Stem Cell Study}

All protocols were approved by the IACUC of Legacy Research and Technology Center. A bilateral compartment syndrome injury was produced in the anterior tibialis muscles by infusing porcine plasma directly into the muscles. A standardized bone marrow collection procedure was used as previously described [34], with bone marrow harvested from the tibia of anesthetized swine. Bone marrow was transferred to an automated cell processing system, BioSafe SEPAX cell separating system (Biosafe SA, Bern, Switzerland), within 60 minutes of collection, and mononuclear cells were isolated. Each sample was divided into 5 aliquots, which were stained for surface marker expression as summarized in Table 1. All samples were acquired using a $\mathrm{BD}^{\mathrm{TM}}$ LSR II flow cytometer.

To identify ckit (a.k.a stem cell factor (SCF)) expression, a porcine SCF ligand conjugated with biotin, kindly provided by Dr. Christene Huang (Transplantation Biology Research Center at Massachusetts General Hospital), was used together with a streptavidin-PE (Jackson Immunoresearch, West Grove, PA) for secondary binding. The antibodies for the other markers were all commercial monoclonal antibodies which were specific for porcine antigens or were anti-human or anti-mouse which cross react with the designated epitopes in swine: CD29-FITC, CD146-FITC and CD105 (GeneTex Inc., Irvine, CA), CD90-APC and CD44-APC-Cy7 (BioLegend, San Diego, CA), CD56-PE-TR (Invitrogen,
Carlsbad, CA), Sca-1-Alexa Fluor 700 (Sca-1-AF700), CXCR4-PE-Cy7 (eBioscience, San Diego, CA), CD31-PE (AbD Serotec, Raleigh, NC), CD144-PE (Santa Cruz Biotechnology, Santa Cruz, CA), and VEGFR2-APC (R\&D Systems, Minneapolis, MN). The anti-CD105 antibody was conjugated with Pacific Blue using a monoclonal antibody labeling kit (Invitrogen, Carlsbad, CA), following manufacturer's protocol.

\section{Systems and Software}

While the details of the data analysis approach are provided in the Results, we highlight the system components below. The "Expander" program for deriving all possible phenotypes or sets is implemented in the Java programming language, and is freely available upon request. Input consists of a comma-delimited file containing fields for absolute set or phenotype names, 3 additional qualifiers, and the percentage of cells in the set specified by the name and the qualifiers. Output consists of a comma-delimited file containing fields for 3 qualifiers, the relative set name, and the derived data value. The three qualifiers from the input are passed to corresponding rows in the output without modification. These qualifiers support downstream analysis based on characteristics such as donor, time point, and treatment protocol. Representative input and output formats are shown in Table 3. Relative set names and their derivation are illustrated in Figure 1 and described in the associated results. The derived data values are simply the sum of the frequencies of the relevant subsets. The output was then loaded into a relational database (MySQL), and standard SQL statements and graphing utilities were used to interrogate the data. Statistical tests were performed using the $\mathrm{R}$ software environment for statistical computing (http://www.r-project.org). 


\section{Table 3 Representative input and output for the "Expander" program}

\begin{tabular}{|c|}
\hline Representative Input \\
\hline $\mathrm{CCR} 7+\mathrm{CD} 45+\mathrm{CD} 57-\mathrm{CD} 27+\mathrm{CD} 28-$, panel, EA02, LTM, 2.48 \\
\hline CCR7+CD45+CD57-CD27+CD28+, panel, EA02, LTM, 5.41 \\
\hline CCR7+CD45+CD57+CD27-CD28-, panel, EA02, LTM, 1.47 \\
\hline CCR7+CD45+CD57+CD27-CD28+, panel, EA02, LTM, 0.22 \\
\hline CCR7+CD45+CD57+CD27+CD28-, panel, EA02, LTM, 0.34 \\
\hline $\mathrm{CCR} 7+\mathrm{CD} 45+\mathrm{CD} 57+\mathrm{CD} 27+\mathrm{CD} 28+$, panel, EA02, LTM, 1.34 \\
\hline Representative Output \\
\hline panel, EA02, LTM, +++++, 1.34 \\
\hline panel, EA02, LTM, ++++-, 0.34 \\
\hline panel, EA02, LTM, ++++., 1.68 \\
\hline panel, EA02, LTM, +++-+, 0.22 \\
\hline panel, EA02, LTM,+++-, 1.47 \\
\hline panel, EA02, LTM, +++-.,1.69 \\
\hline panel, EA02, LTM,+++.+, 1.56 \\
\hline panel, EA02, LTM,+++.-,1.81 \\
\hline $\begin{array}{l}\text { The Expander program derives aggregate sets or supersets from input data, } \\
\text { and outputs both the relative set name and the percentage of cells in both } \\
\text { the newly derived sets and the original sets. The percentage of cells in the } \\
\text { derived sets is calculated by adding together the percentages in the subsets, } \\
\text { as illustrated in Figure } 1 \text {. The rows below illustrate the format of both input } \\
\text { and output, but not direct correspondence between input and output. Output } \\
\text { is loaded into a relational database for further analysis. }\end{array}$ \\
\hline
\end{tabular}

\section{Statistical Methods}

In the melanoma vaccine study, the Wilcoxon signedrank test was used to identify either increased expression between time points or decreased expression between time points, depending on the pair of time points under consideration. The $\mathrm{p}$-values were then used to screen populations for biologically meaningful results. These $\mathrm{p}$-values provided a simple, well-understood metric to encapsulate the differences between the two time points. An alternative metric, such as 4 of 7 donors showing at least a $5 \%$ change between time points, would have been more verbose and would have required more detailed justification. In the porcine wound healing study, the Wilcoxon rank sum test was used to identify phenotypes in which the wounded cohort showed a greater change from baseline than did the control cohort.

\section{Results}

\section{Exhaustive Expansion}

In both studies, standard FCM analysis software was used to establish positive and negative gates based on the use of "fluorescence-minus-one" (FMO) controls for the included markers. In the case of the 5 memory markers used in the melanoma vaccine study, $32\left(2^{5}\right)$ sets were subsequently generated using WinList's ${ }^{\mathrm{sm}}$ (http:// www.vsh.com) FCOM function. Such combination gates also can be generated with other flow cytometry analytical software such as FlowJo (http://www.flowjo. com) and FCS Express (http://www.denovosoftware. com). The gating strategy for this study is illustrated in Figure 1. By inspecting a series of two-dimensional scatter plots, positive and negative gating boundaries were set, dividing the cells into subpopulations. Each of the 4 quadrants in dot plots 1 through 4 illustrates the frequencies of phenotypes of gp100 tetramer ${ }^{+} \mathrm{CD} 8^{+} \mathrm{T}$ cells that are defined by positive and negative combinations of CCR7, CD45RA, CD57, CD27, and CD28.

Next we derived the percentage of cells in the more comprehensive analysis of all $243\left(3^{5}\right)$ possible phenotypes, as defined by $0,1,2, \ldots 5$ parameters, using a custom Java program as described in the Methods. We utilize a shorthand notation for phenotypes by introducing a placeholder (".") to represent an unspecified parameter. These concepts are also illustrated in Figure 1, in which the callout table shows the shorthand notation for 2 populations specified by 5 markers, CCR7 + CD45RA-CD57-CD27+CD28+ (+-++) and CCR7 + CD45RA-CD57-CD27+CD28- (+-+-). The table also shows the notation for the 4 marker phenotype $(+-+$.) resulting from the summation of the frequencies of the two 5 marker phenotypes. Notice that CD28 assumes 3 values, "+", "-", and ".". The phenotype +-+. represents the combination or union of two subphenotypes or subsets $(+-++$ and +-+-$)$, Hereafter, subphenotype signatures will be referred to as either sets or phenotypes.

The universal set $(\ldots \ldots)$ contains $100 \%$ of the cells in the population of interest (e.g. viable, antigen-positive, $\mathrm{CD} 8^{+}$cells), and thus serves as an internal control. All other sets are proper subsets of the universal set. As presented here, Exhaustive Expansion applies to binary classification systems (e.g. positive and negative gating), but extension to n-ary classification systems (e.g. dim, intermediate, bright) is possible. After derivation of frequencies for all sets, data was loaded into a relational database (MySQL) and analyzed with SQL statements and graphing utilities.

\section{Melanoma Vaccine Study Average CV Suggests Stable CD27, CD28, and CD45RA Expression Over Time}

Having derived the percentage of cells in all 2430 through 5-parameter sets in the melanoma vaccine study, we generated longitudinal profiles for all sets as shown by the example in Figure 2. This enabled us to clearly see the responses of each donor over time. Additionally, these profiles allow each donor to serve as his or her own control. Next, we looked for sets that were interesting based on coefficient of variation $(\mathrm{CV}$, standard deviation divided by mean). We computed Average $\mathrm{CV}$ by calculating $\mathrm{CVs}$ for each donor across 3 time 


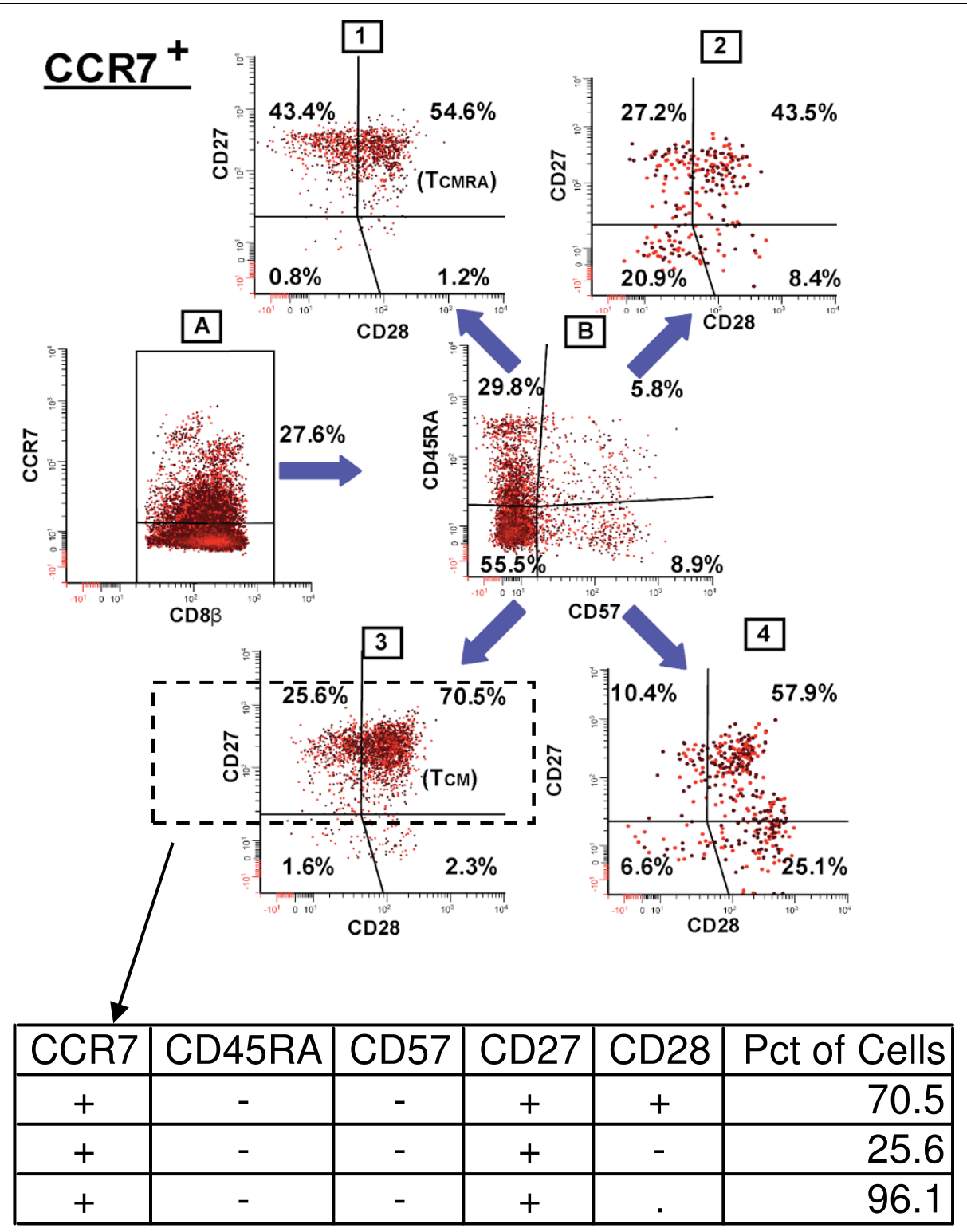

Figure 1 Representative gating strategy and additional phenotype set calculations. This figure illustrates a gating strategy in which CCR ${ }^{+}$ cells are further categorized by positive or negative expression of CD45RA and CD57. Cells in each resulting quadrant (dot plot B) are then categorized based on CD27 and CD28 staining frequencies (dot plots 1-4). The callout table illustrates how the two phenotypes CCR7+CD45RACD57-CD27+CD28+ (+-++) and CCR7+CD45RA-CD57-CD27+CD28- (+-+-), marked by dotted lines, are aggregated to form a superset population, CCR7+CD45RA-CD57-CD27+ (+-+.), in which CD28 expression is unspecified.

points, and then averaging the $7 \mathrm{CVs}$. We then sorted the longitudinal profiles both by ascending average $\mathrm{CV}$ and descending average $\mathrm{CV}$. In this data, the sets with a low average CV, as shown in Figure 2, were particularly interesting because of their common use in lower order flow cytometry analysis to distinguish central memory and effector memory $\mathrm{T}$ cells $[35,36]$. At $8.59 \%$, the CD45RA+ phenotype has the lowest Average CV of all 242 non-universal sets (those with at least one marker specified). In this case, even though there is inter-donor variation, the values are relatively stable over time for each individual donor. There are 4 donors with relatively low levels of CD45RA expression, 2 donors with relatively high levels, and 1 donor with an intermediate level. Thus, inspection reveals that the low Average CV was associated with donor stratification. Profiles for CD27+ and CD28+ are also shown in Figure 2, and similarly suggest overall low average CVs for individual patient phenotype frequencies over all 3 time points, but do not indicate inter-donor variation. Notably, all three 


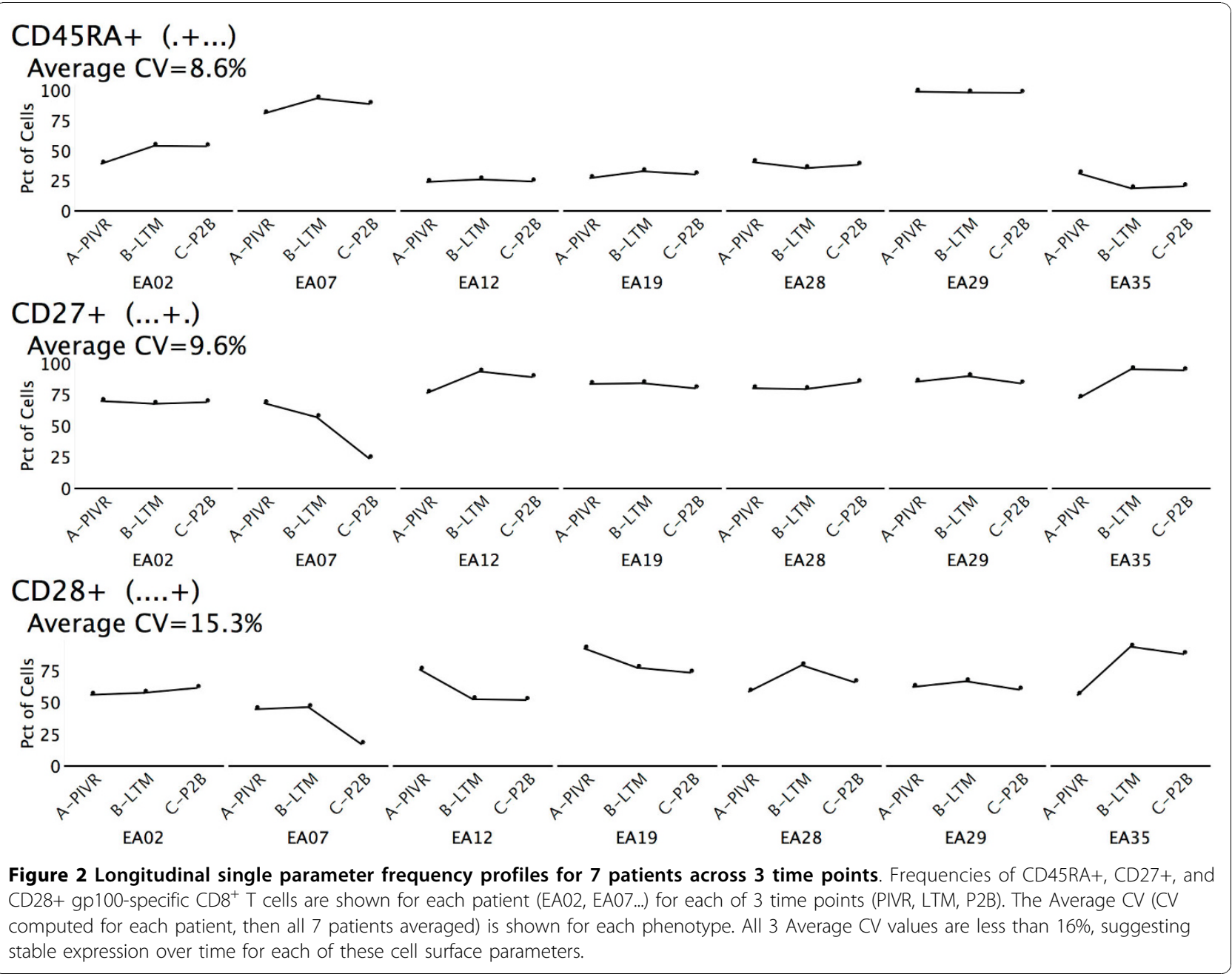

of these markers are associated with the $\mathrm{T}_{\mathrm{CM}}$ consensus phenotype (CCR7+ CD45RA- CD57- CD27+ CD28+) predicted from lower order 3- and 4-marker flow cytometry analysis, yet individually show low to moderate frequency changes over the time course of the vaccine study, even though our previous data suggested $\mathrm{T}_{\mathrm{CM}}$ increased at LTM for most patients [8]. Since several studies have shown that early effector-memory $\mathrm{T}$ cells $\left(\mathrm{T}_{\mathrm{EM}}\right)$ are also CD45RA- $\mathrm{CD} 27+\mathrm{CD} 28+[8,35,36]$, the stability in expression of each of these single markers over time may reflect the redistribution of gp100-specific memory $\mathrm{CD}^{+} \mathrm{T}$ cells from the $\mathrm{T}_{\mathrm{EM}}$ to the $\mathrm{T}_{\mathrm{CM}}$ phenotype compartment at LTM. Conversely, by this line of reasoning, higher frequencies of memory $\mathrm{T}$ cells may be expected to be distributed in the $\mathrm{T}_{\mathrm{EM}}$ phenotype compartment after antigen challenge at PIVR and P2B.

Peak Finding Algorithm Highlights Central-Memory-Like Phenotype

Arguably, in situations of acute primary antigen challenge, such as the gp-100 vaccine regimen, central memory phenotypes $\left(\mathrm{T}_{\mathrm{CM}}\right)$ should be more predominant 18 to 24 months after antigen exposure, represented by a peak frequency at time point B (LTM). Both effector and early and late stage effector memory phenotypes should be more predominant after recent secondary antigen exposure, represented by an increase in these phenotypes (and a concomitant decrease in $\mathrm{T}_{\mathrm{CM}}$ ) following boosting immunizations at time point C (P2B). Thus, to identify specific patterns of longitudinal changes, we computed p-values (Wilcoxon signed-rank test, a paired test) between pairs of time points for each phenotype.

To identify the $\mathrm{T}_{\mathrm{CM}}$ peaks, we looked for phenotypes that showed a statistically significant increase from $A$ to $\mathrm{B}$, and a concomitant decrease from $\mathrm{B}$ to $\mathrm{C}$. Twenty three sets met these criteria with $\mathrm{p}$-values less than 0.05 . Eleven sets met these criteria with p-values less than 0.01 . We inspected the longitudinal profiles for all 11 sets to verify the presence of reasonable peaks. We did not correct for multiple comparisons because we simply 
used the p-values as a numeric indicator of changes across the population, giving us direction for visual inspection. Furthermore, we did not make family-wide conclusions about the statistical significance of the peaks. We call the algorithm used in this analysis a "peak finding algorithm." A similar approach could be used to find valleys.

Eight of the 11 sets with p-values less than 0.01 were supersets of the consensus $\mathrm{T}_{\mathrm{CM}}$ phenotype CCR7 + CD45RA-CD57-CD27+CD28+ (+-++). These sets and the relationships between them are illustrated in the directed acyclic graph (DAG) shown in Figure 3. Since we derived supersets of cells by combining sets, this set inclusion hierarchy provides a tool to visualize the relationships between these sets. The terminal node of the DAG is the consensus $\mathrm{T}_{\mathrm{CM}}$ phenotype of CCR7 +CD45RA-CD57-CD27+CD28+ (+-++). Figures 4A, 4B, and $4 \mathrm{C}$ illustrate the behavior of this phenotype over time. Figure 4A illustrates the changes from time point A to $B$ for all 7 donors, while Figure $4 B$ illustrates the changes from $B$ to $C$. Figure $4 C$ shows the longitudinal profile for all donors. The 4 CD45RA+ "low" donors, identified in Figure 2, exhibited correspondingly similar higher frequencies of the consensus $\mathrm{T}_{\mathrm{CM}}$ phenotype at time point $B$ (LTM), and are shown on the left side of Figure 4C.

One of the phenotypes identified by the peak-finding algorithm was CCR7+CD57-CD27+CD28+ $(+.-++)$, in which CD45RA is unspecified, and therefore includes both the CD45RA+ putative $\mathrm{T}_{\mathrm{CM}}$ precursor phenotype $\left(\mathrm{T}_{\text {CMRA }}\right)$ and the CD45RA- $\mathrm{T}_{\mathrm{CM}}$ phenotype. The longitudinal profile for this set is shown in Figure $4 \mathrm{C}$, and shows that 6 of 7 patients clearly peak at time point $B$.
If the basic assumption that circulating gp100 specific $\mathrm{CD}^{+} \mathrm{T}$ cells which are maintained 1-2 years after initial antigen exposure are both $\mathrm{T}_{\mathrm{CM}}$ and $\mathrm{T}_{\mathrm{CMRA}}$ is correct, this data confirms that CD45RA staining may not be obligate in identifying all long term central memory $\mathrm{T}$ cell subpopulations. This interpretation is reinforced by the donor-level consistency in CD45RA expression over time as illustrated in Figure 2. Fundamentally, if 3 donors (e.g. EA02, EA07, EA29) have relatively consistently high/intermediate frequencies of CD45RA staining over time, they are unlikely to show a peak in the 5marker consensus phenotype characterized by negative expression of CD45RA at the LTM time point when frequencies of central memory subpopulations should be elevated. Similarly, CD27+ and CD28+ staining may not be obligate descriptors for $\mathrm{T}_{\mathrm{CM}} / \mathrm{T}_{\mathrm{CMRA}}$ subpopulations since staining frequencies for both remain relatively stable (low average CVs - Figure 2) over time, and may simply reflect memory $\mathrm{T}$-cell redistribution between $\mathrm{T}_{\mathrm{EM}}$ and $\mathrm{T}_{\mathrm{CM}} / \mathrm{T}_{\mathrm{CMRA}}$ phenotype compartments. Concomitant CCR7+CD57- staining may prove to be a more definitive minimal obligate phenotype signature for $\mathrm{T}_{\mathrm{CM}} / \mathrm{T}_{\mathrm{CMRA}}$ subpopulations. This is suggested by the observations that 6 of 7 patients show CCR7+CD57peaks at LTM (Figure 4C), and that 7 of the 9 sets in Figure 3 are subsets of the CCR7+CD57- $(+.-\ldots)$ phenotype.

\section{Porcine Stem Cell Study}

Screening of Thousands of Subpopulations Identifies Novel Stem Cell Phenotype

In the porcine wound-healing study, Exhaustive Expansion was applied to 5 different 8-parameter data sets

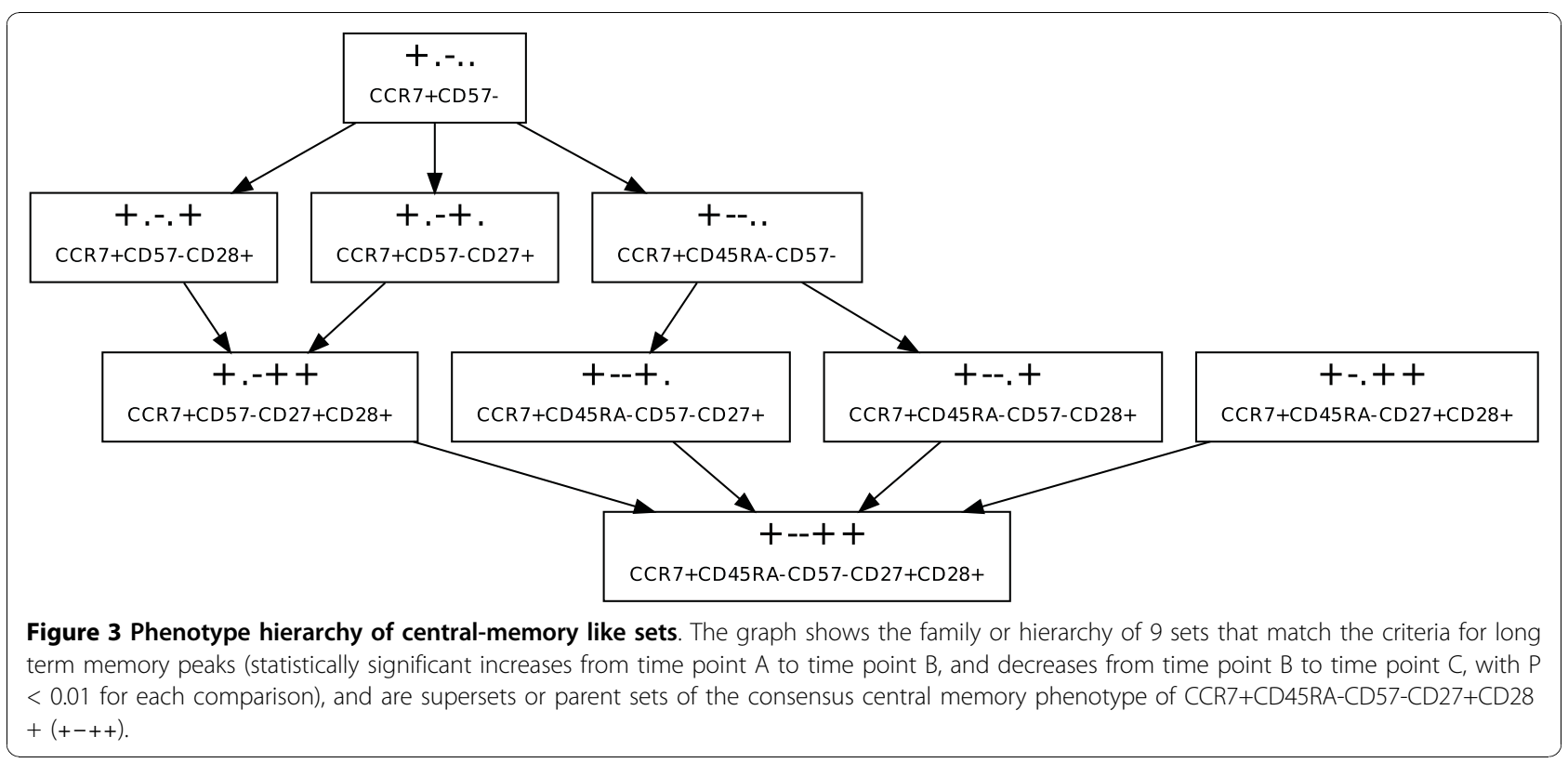




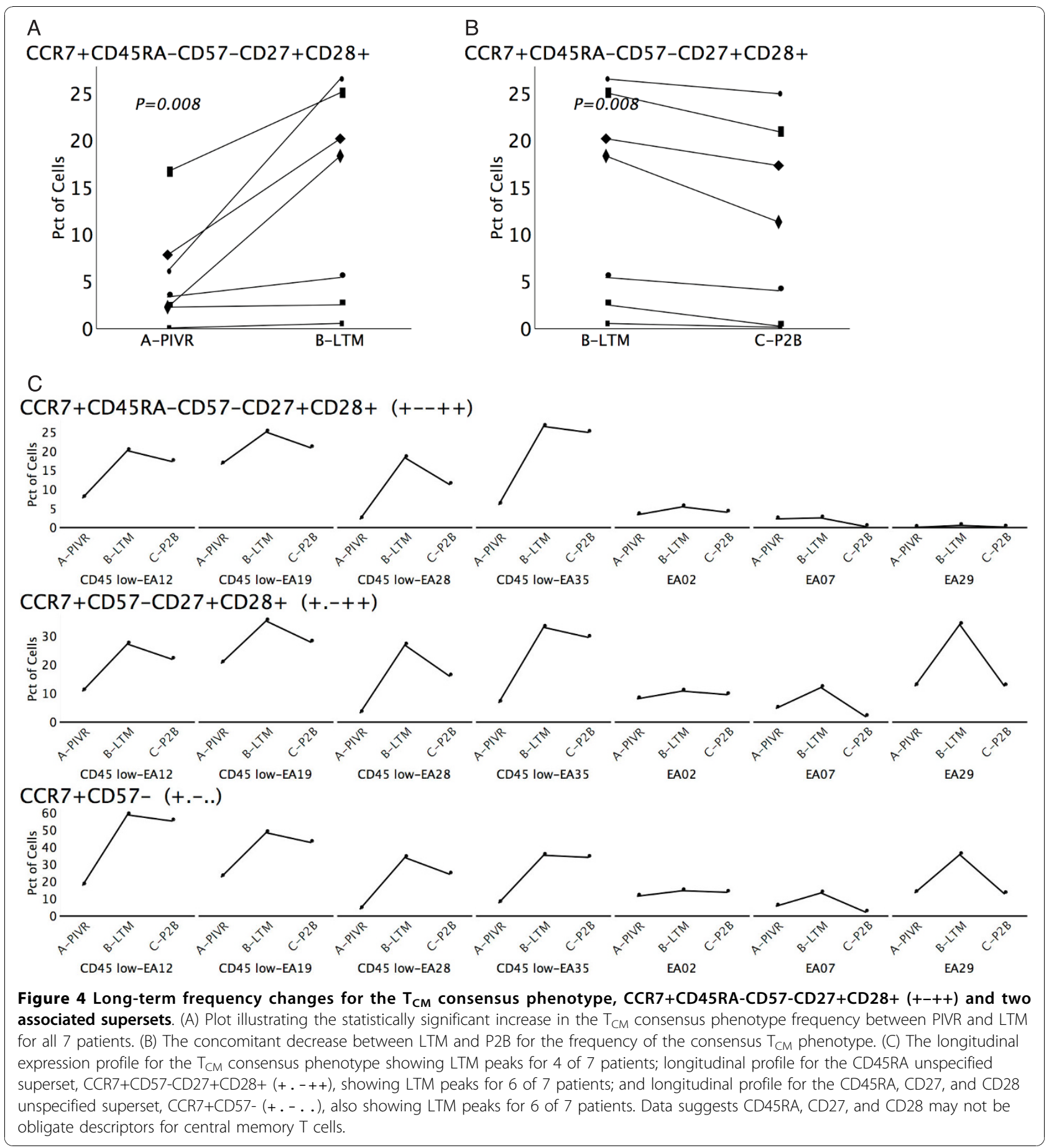

generated using WinList's FCOM function, after setting positive and negative staining regions for each marker with FMO controls. This resulted in delineation of 6,561 $\left(3^{8}\right)$ sets per sample per panel. Next, we computed changes from baseline (e.g. week 1 results minus week 0 results) for all phenotypes for all donors for weeks 1 through 4. We did not see clear kinetic changes in this data over the 4 week period, perhaps because these changes occurred much earlier, during the interval between week 0 and week 1 , when no samples were drawn. Thus, to look for changes from baseline across the time frame of the study, we averaged the change from baseline data for each donor for each cell population over the 4 observations made in week 1 through week 4 . Hereafter, we refer to this metric as the average delta value. 
Additionally, we defined a process control range, based on analysis of 6 aliquots from a single animal drawn at a single point in time. For each phenotype, the process control range was defined as the maximum frequency value of the 6 replicates minus the minimum frequency value. This provided a conservative approach to quantifying the precision of our assay, and allowed us to focus on phenotypes with readouts exceeding the process control range.

Next, to identify populations of numeric interest, we identified sets in which 6 or more (out of 8 ) wounded animals had an average delta greater than the process control range, and 6 or more control animals had an average delta less than or equal to the process control range. The resulting 122 sets $(0.4 \%$ of the total 32,805 sets) came from three of the five panels, with two panels having no sets that matched these criteria. Of the 122 sets, 76 had p-values (Wilcoxon rank sum, one-sided) less than 0.05 . Twenty-three of these 122 phenotypes were positive for CD29 ( $\beta 1$-integrin) and CXCR4, which are indicative of muscle progenitor cells in mouse models [25,37]. All of these CD29+CXCR4+ sets were from the CD31 panel. Initially, none of these sets showed statistically significant differences between wounded and control populations, due at least in part to the presence of an outlier in the control group, as shown by the scatter plots in Figure 5A. This outlier was driven by an unusually large observation for one of the donors, which in the case of the CD29+CD31+CD56+CXCR4+CD90 + Sca1-CD44+ $(++++.+-+)$ phenotype was an extreme outlier (greater than quartile 3 plus 3 times the interquartile range), and nearly twice as large as the next largest observation $(.31 \%$ versus $.17 \%)$. This outlier observation from week 4 for control animal C-P1120 is illustrated in Figure 5D. When this animal was removed from the analysis, all 23 of the CD29+CXCR4+ phenotypes showed statistically significant differences between the control and wounded animals. Two of these phenotypes are shown in Figures $5 \mathrm{~B}$ and $5 \mathrm{C}$. Figure 5B shows the same phenotype as Figure $5 \mathrm{~A}$, only with the outlier removed. As the scatter plot shows one point per donor it better illustrates the details of the data than does a bar plot or box plot. Additionally, Figures 5A, B, and 5C have a reference line indicating the process control range. The $23 \mathrm{CD} 29+\mathrm{CXCR} 4+$ phenotypes, itemized in Table 3, may represent different bone-marrow-derived mesenchymal progenitor cell populations mobilized in response to myonecrotic injury and capable of endothelial, chondrogenic, and myogenic differentiation. Notably, the superset CD29+CXCR4+CD90+ (Figure 5C) is common to 19 of the phenotypes in Table 4. As such it may indicate a minimum obligate progenitor cell phenotype.

\section{Discussion}

Here we have applied Exhaustive Expansion to two very different translational studies to demonstrate its broad application and utility. In each analysis, we generated all possible cell sets for each sample. Then we identified interesting sets based on coefficients of variation and long term memory peaks in the melanoma vaccine study, and separation between test and control cohorts in the wound healing study.

Analysis of data from multiparameter flow cytometry experiments consists of two main activities with well defined separation of concerns. First, events are gated into cell sets of interest using either manual or automatic techniques. Second, summary statistics describing these sets of cells are analyzed to identify meaningful experimental results. Exhaustive Expansion touches on both of these activities. In the case where positive/negative boundaries can be established for multiple markers, our Expander logic allows us to define a large number of supersets by exhaustively combining constituent subsets. Next, we identify features of interest such as Average CV, peaks, and separation between control and test cohorts. Such numeric features can be sorted and filtered, and illustrated with simple graphs. Importantly, these features are calculated for all phenotypes, thereby allowing systematic and relatively unbiased interrogation of the data. Additionally, the use of powerful mature software tools such as Java, MySQL, and R provides us with the flexibility to pursue the data analysis as suggested by the data itself and the underlying science.

For example, while we used a statistical test to quantify peaks in the melanoma study, we could have defined peaks based on an average fold change between time points (e.g. greater than 3), or on a criteria such as at least 4 donors showing at least a 5 percentage point change between time points. Alternatively, we could identify all phenotypes with a larger change than that shown by a predicted consensus phenotype. Or if we were interested in rare events, we could select sets in which less than 2 cells at baseline expanded to more than 20 cells after treatment. When a filter identifies many sets, the filter can be made more stringent. Alternatively, filters can identify a specific number or percentage of sets, such as the 10 sets with the largest average fold changes between two time points. Additionally, sets can be sorted on numeric characteristics such as fold change, $\mathrm{p}$-value, or Average CV. This allows us to inspect sets ranked from largest to smallest fold change, for example, and perhaps further refine a threshold criteria based on some meaningful feature in the data. All of these numeric thresholds can and should be adjusted based on experimental conditions, assay precision, and the biological questions under investigation. 


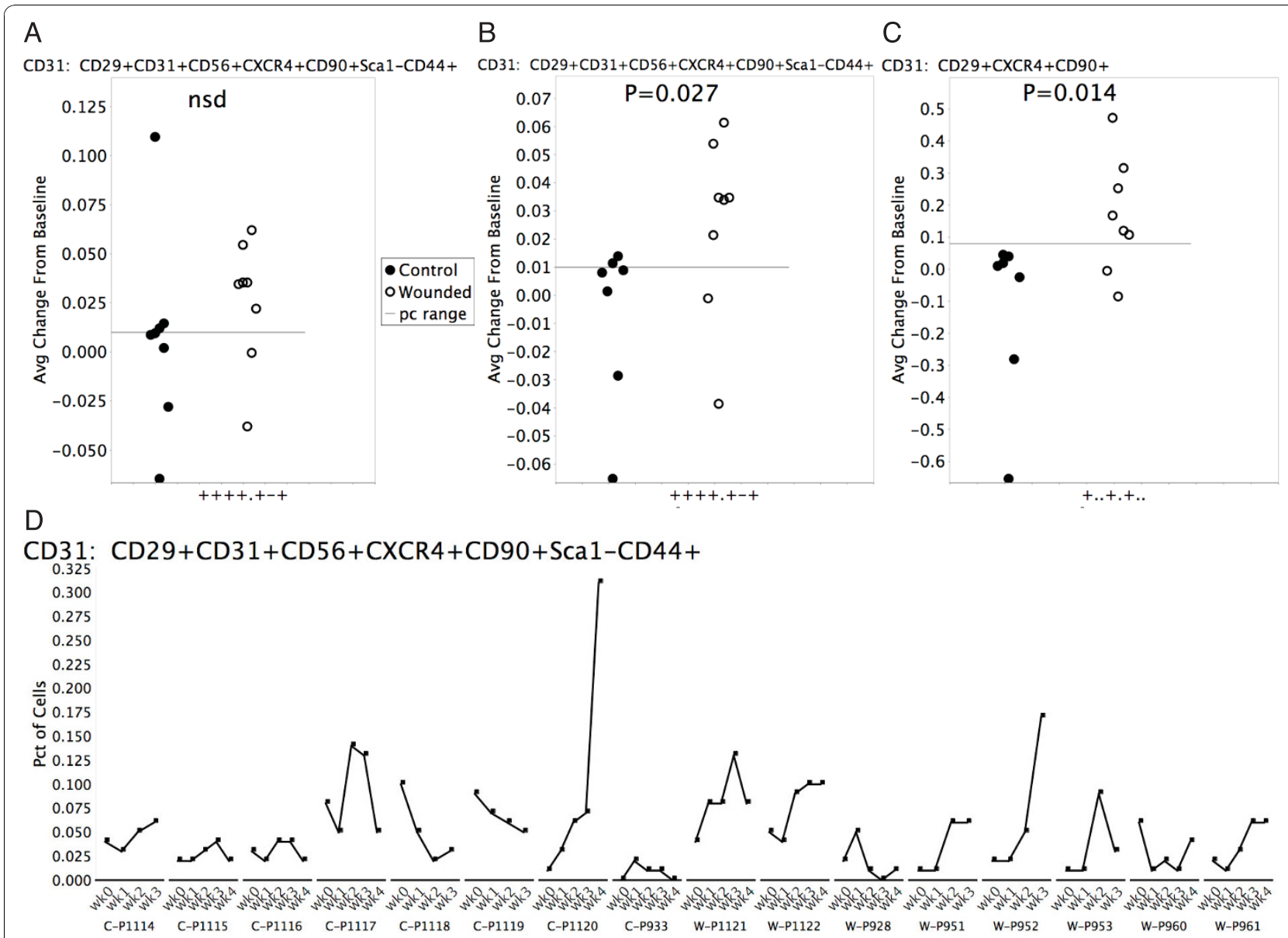

Figure 5 Differences between control and wounded animals for 2 phenotypes from the CD31 panel. (A) Average frequency change from baseline (average of frequency differences for week 1 minus week 0 , week 2 minus week 0 , week 3 minus week 0 , and week 4 minus week 0 ) is shown for control animals (solid circles) versus wounded animals (open circles) for phenotype CD29+CD31+CD56+CXCR4+CD90+Sca1-CD44+ + .++++-+ ). The horizontal line represents the process control range (maximum frequency minus minimum frequency, calculated from 6 replicate samples) for this phenotype. There is no significant difference between the cohorts, due in part to the outlier at approximately 0.115 for one animal in the control cohort. (B) The same phenotype analysis with outlier removed shows a statistically significant difference between wounded and control cohorts. (C) Frequency differences between wounded and control animals for the phenotype superset, CD29+CXCR4 $+\mathrm{CD} 90+(+\ldots+.+\ldots)$, which was common to 19 of the putative myogenic precursor phenotypes shown in Table 4. (D) Longitudinal profiles for all animals for week 0 through week 4 for set CD29+CD31+CD56+CXCR4+CD90+Sca1-CD44+ (++++.+-+). Control animals indicated by C, Wounded by W. Note the week 4 outlier on control animal C-P1120. This animal was removed from the analysis shown in (B) and (C).

Adoptive transfer of tumor specific $\mathrm{T}$ cells in cancer immunotherapy translational studies has previously emphasized the transfer of highly differentiated, end stage effector $\mathrm{T}$ cells from in vitro IL-2 supported expansion cultures. More recently, compelling data from mouse tumor models suggests that tumor specific $\mathrm{T}_{\mathrm{CM}}$ and very early $\mathrm{T}_{\mathrm{CM}}$ precursors, referred to as central memory stem cells $\left(\mathrm{T}_{\mathrm{SCM}}\right)$, express elevated proliferation potential, enhanced long term survival in vivo, and give rise to activated CTLs in vivo with superior cytolytic activity compared to effector memory $\left(\mathrm{T}_{\mathrm{EM}}\right)$ or effector $\left(\mathrm{T}_{\mathrm{EFF}}\right) \mathrm{T}$ cells from in vitro expansion cultures [9]. Adoptive transfer immunotherapy strategies based on the in vitro expansion of $\mathrm{T}_{\mathrm{CM}}$ and $\mathrm{T}_{\mathrm{SCM}}$ subpopulations may offer significant clinical advantage in treating cancer patients if the human phenotype signatures for $T_{C M}$ and $\mathrm{T}_{\mathrm{SCM}}$ can be identified, and rapid efficient recovery procedures are developed to recover memory cells for subsequent in vitro expansion [38-40].

Previously, in a clinical study of long term tumor specific $\mathrm{T}$ cell memory function in melanoma patients, we elucidated the multiparameter phenotype of tumor specific $\mathrm{T}_{\mathrm{CM}}(\mathrm{CCR} 7+\mathrm{CD} 45 \mathrm{RA}-\mathrm{CD} 57-\mathrm{CD} 27+\mathrm{CD} 28+)$, and a second potentially early $\mathrm{T}_{\mathrm{CM}}$ precursor which we referred to as $\mathrm{T}_{\text {CMRA }}$ (CCR7+CD45RA+CD57-CD27 $+\mathrm{CD} 28+$ ) [8]. Gp100-specific $\mathrm{T}_{\mathrm{CMRA}}$ shares its phenotype with naive $\mathrm{CD}^{+} \mathrm{T}$ cells, and thus may be similar to the $\mathrm{T}_{\mathrm{SCM}}$ subset described in the mouse. Sorting 
Table 423 CD29+CXCR4+ subsets showing significant differences between wounded and control animals

\begin{tabular}{|c|c|c|c|}
\hline Panel & Relative Set Name & Absolute Set Name & P-Value \\
\hline CD31 &.+++++-+ & CD29+CD31+CD56+CXCR4+CD90+Sca1-CD44+ & 0.027 \\
\hline CD31 &.+++++- & CD29+CD31+CD56+CXCR4+CD90+Sca1- & 0.027 \\
\hline CD31 &.+++-+-+ & CD29+CD31+CXCR4+CD105-CD90+Sca1-CD44+ & 0.036 \\
\hline CD31 &.+++-+- & CD29+CD31+CXCR4+CD105-CD90+Sca1- & 0.036 \\
\hline CD31 &..+++--+ & CD29+CD31+CXCR4+CD105-Sca1-CD44+ & 0.027 \\
\hline CD31 &...+++-- & CD29+CD31+CXCR4+CD105-Sca1- & 0.028 \\
\hline CD31 &..++++-+ & CD29+CD31+CXCR4+CD90+Sca1-CD44+ & 0.027 \\
\hline CD31 &..++++- & CD29+CD31+CXCR4+CD90+Sca1- & 0.027 \\
\hline CD31 &...+++++ & CD29+CD31+CXCR4+CD90+CD44+ & 0.02 \\
\hline CD31 &...++++ & CD29+CD31+CXCR4+CD90+ & 0.02 \\
\hline CD31 & +-++- & CD29+CD31-CD56+CXCR4+CD105-CD90-Sca1- & 0.027 \\
\hline CD31 &.+++-+-+ & CD29+CD56+CXCR4+CD105-CD90+Sca1-CD44+ & 0.02 \\
\hline CD31 &.+++-+- & CD29+CD56+CXCR4+CD105-CD90+Sca1- & 0.02 \\
\hline CD31 &..+++-++ & CD29+CD56+CXCR4+CD105-CD90+CD44+ & 0.02 \\
\hline CD31 &.$+++-+\ldots$ & CD29+CD56+CXCR4+CD105-CD90+ & 0.02 \\
\hline CD31 &..++++-+ & CD29+CD56+CXCR4+CD90+Sca1-CD44+ & 0.02 \\
\hline CD31 &...++++- & CD29+CD56+CXCR4+CD90+Sca1- & 0.02 \\
\hline CD31 &...+++++ & CD29+CD56+CXCR4+CD90+CD44+ & 0.02 \\
\hline CD31 &..$++++\ldots$ & CD29+CD56+CXCR4+CD90+ & 0.02 \\
\hline CD31 & $+\ldots+-+.+$ & CD29+CXCR4+CD105-CD90+CD44+ & 0.014 \\
\hline CD31 & $+\ldots+-+\ldots$ & CD29+CXCR4+CD105-CD90+ & 0.014 \\
\hline CD31 & $+\ldots+.+.+$ & CD29+CXCR4+CD90+CD44+ & 0.014 \\
\hline CD31 & $+\ldots+.+\ldots$ & CD29+CXCR4+CD90+ & 0.014 \\
\hline
\end{tabular}

Relative set name, absolute set name, and p-value (Wilcoxon rank sum, one-sided) are shown. P-values are calculated excluding data for one outlier control animal. These are also sets in which at least 6 of 8 wounded animals show average delta readouts greater than the process control range.

strategies to select for these highly defined putative central memory populations could thus be implemented prior to cytokine-mediated in vitro expansion and adoptive transfer. However, recovery strategies based on a more simple minimal obligate phenotype signature would facilitate the more rapid, efficient recovery of larger numbers of cells using bulk techniques such as magnetic bead separation. Exhaustive Expansion identified a possible minimal obligate $\mathrm{T}_{\mathrm{CM}} / \mathrm{T}_{\mathrm{CMRA}}$ phenotype (CCR7 + CD57-: Figure 4) that was common to $7 / 8$ of the CCR7+ CD45RA-CD57-CD27+CD28+ supersets that showed frequency peaks at LTM (Figure 3 ). This putative minimal obligate $\mathrm{T}_{\mathrm{CM}} / \mathrm{T}_{\mathrm{CMRA}}$ phenotype signature may thus facilitate the recovery of $\mathrm{T}_{\mathrm{CM}} / \mathrm{T}_{\mathrm{CMRA}} \mathrm{T}$ cells, and cells from the intermediate stages of the $\mathrm{T}_{\mathrm{CMRA}}$ to $\mathrm{T}_{\mathrm{CM}}$ to $\mathrm{T}_{\mathrm{EM}}$ differentiation pathway represented by the other superset phenotypes in Figure 3. Clearly, additional experiments, including functional assays, are required to validate the hypothesis that CCR7+CD57- is a minimal obligate phenotype for $\mathrm{T}_{\mathrm{CM}}$.

A second somewhat unexpected outcome of Exhaustive Expansion of the melanoma specific $\mathrm{CD}^{+} \mathrm{T}$ cell memory response was the suggestion that the combined frequency of tumor-specific $\mathrm{T}$ cells which express either the $\mathrm{T}_{\mathrm{CM}}$ or $\mathrm{T}_{\mathrm{EM}}$ phenotypes may not change appreciably over the course of the primary antigen challenge, long term memory maintenance, and following boosting immunization. The frequencies of gp100 specific $\mathrm{T}$ cells expressing key individual identifiers for the resolution of $\mathrm{T}_{\mathrm{CM}}$ and early $\mathrm{T}_{\mathrm{EM}}$ cells, such as CD45RA, CD27 and CD28, did not change appreciably across all three time points in the study (Figure 2). This may be explained in part by the observation that $\mathrm{T}_{\mathrm{CM}}$ and $\mathrm{T}_{\mathrm{EM}}$ phenotypes share the CD45RA-CD27+CD28+ signature $[8,35,36]$. The expression stability for each individual marker may suggest that, although cells may transition between the $\mathrm{T}_{\mathrm{CM}}$ and $\mathrm{T}_{\mathrm{EM}}$ phenotype compartments due to homeostasis-driven or antigen-stimulated proliferation, the overall combined frequency of the $\mathrm{T}_{\mathrm{CM}}$ plus $\mathrm{T}_{\mathrm{EM}}$ memory $\mathrm{T}$ cell pool as a fraction of all antigen specific $\mathrm{T}$ cells remains relatively constant. Thus, absolute numbers of cells in each compartment, and even the ratio of the frequency of cells with each phenotype, can fluctuate; but the total combined memory $\mathrm{T}$ cell frequency (i.e. $\mathrm{T}_{\mathrm{CM}}+$ $\mathrm{T}_{\mathrm{EM}}$ ) may remain relatively stable after primary immunization. This observation has important implications for 
the optimal design of primary immunization strategies in both infectious disease and cancer vaccine settings.

In the stem cell study, 8 color staining panels that included mAbs previously employed in lower-order panels to delineate mesenchymal cells (CD29, CD90, and CD44), primitive pluripotent stem cells (ckit, CXCR4, and Sca-1), differentiated myoblasts (CD56 and CXCR4), and vascular-relative cells (CD146, CD31, CD144, CD105, and VEGFR2) were used to more comprehensively characterize significant changes in bonemorrow-derived putative mesenchymal progenitor cell populations following myonecrotic injury. Our data analysis technique allowed us to identify novel populations by focusing on phenotypes that showed both statistically significant differences between wounded and control animals and credible readouts above the process control range.

Studies have demonstrated that injection of bone marrow stem cells into ischemic muscle can reduce the damage to the muscle and the loss of muscle function [17]. Bone marrow contains stem and progenitor cells which can differentiate into specific cell types such as myoblasts, chondrocytes, and endothelial cells in vitro and in vivo [41]. The role of bone-marrow-derived mesenchymal stem cells (MSCs) to directly reconstitute myoblast formation in vivo in damaged muscle is controversial since their main role may be that of augmenting the myogenic potential of resident muscle MSCs referred to as satellite cells [42]. In vitro, bone marrow cells acquire tissue-specific phenotypes when co-cultured with specialized cell types or tissue-derived extracts [41]. These potentially multipotent cells may be mobilized in the bone marrow and recruited into muscle tissue where they mitigate tissue damage following acute myonecrotic injury. Our results show that cell surface markers can be used to comprehensively track bone marrow phenotype changes associated with muscle injury in porcine compartment syndrome, which are significantly different between the control and wounded groups. Moreover, our results demonstrate that we can detect multiple putative stem and progenitor phenotypes. The large majority of these 23 phenotype subpopulations $(20 / 23)$ appear to share a common minimum obligate phenotype signature (e.g. CD29+CXCR4+CD90 +: Table 4), expressing markers reported to be characteristic of MSC-derived myogenic cells [25,37,43]. However, there may already be lineage-specific heterogeneity expressed by these MSC-like subpopulations in the bone marrow, since approximately half (10/23) expressed the endothelial differentiation marker CD31 [44] and an equal number $(11 / 23)$ expressed the CD56 marker more commonly associated with regenerating muscle fibers and satellite cells[45]. Lineage-specific commitment can be tested by culturing such sorted MSC subsets under lineage-promoting culture conditions [41]. Based on the results presented here, the identification of bone marrow subpopulations by multiparameter FCM might be used to further sort or purify cell sets for autologous cell therapy to regenerate muscle, nerve and vascular tissues in compartment syndrome or other extremity injuries.

There are limitations to this work. First, from a biological perspective, both studies were performed with a small number of subjects. Additional experiments, including correlated memory $\mathrm{T}$ cell and MSC functional assays, are needed to validate the hypotheses generated by this work. Second, from an assay perspective, the analytical approach described here more readily supports those circumstances where orthogonal boundary gates (e.g. positive and negative regions) can be established. Third, from a process control perspective, the process control samples used to identify phenotypes of interest were analyzed on three consecutive days. Controls analyzed over the duration of the study would more accurately calibrate the precision of the assay. Fourth, from a computational perspective, there are practical limits to the scalability of the algorithm. Applying Exhaustive Expansion to an experiment in which there were 10 variable markers would result in a manageable $3^{10}=59,049$ possible phenotypes, while 20 variable markers would result in a challenging $3^{20}=$ $3,486,784,401$ possible phenotypes.

While there is no way to alter the exponential increase in number of phenotypes as a function of the number of markers, it is unlikely that millions or billions of phenotypes would be meaningful, whether due to experimental noise (e.g. too few events to be adequately precise) or underlying biology. Thus, the phenotype search space would be pruned to a more reasonable number of phenotypes. Specific strategies for pruning the search space are beyond the scope of this work, but the general approach would mitigate the scalability impacts of the exponential increase, further extending the applicability of Exhaustive Expansion.

Furthermore, Exhaustive Expansion adds immediate value to contemporary experimental strategies and paves the way for the practical use of increasing numbers of markers. For example, one experimental design commonly published in contemporary literature uses a single fluorophore marker dump channel to exclude certain cells (e.g. CD14+, CD19+ and dead cells), two markers to identify lineage of interest (e.g. CD3 and CD4 or CD8), and another 5 markers to identify functional sets of interest (CD107a, IFN- $\gamma$, IL-2, MIP1 $\beta$, and TNF- $\alpha$ ) $[31,32,46]$. Using this experimental approach, 3 of the 8 total fluorophores are required to identify the parent population, while the other 5 can be considered variable identifiers of subphenotypes of interest. This construct leads to 31 sets of interest $\left(2^{5}-1\right.$, since the universal set is excluded). In 
comparison, we have demonstrated that we can analyze over 32,000 sets, generated by 5 different panels of 8 variable markers. Additionally our approach recognizes that potential sets of interest are both those defined by all variable markers, and those defined by subsets of variable markers. Thus, our approach is readily applicable to contemporary flow cytometry experimental strategies, providing both support for an increasing number of variable markers and exhaustive interrogation of phenotypes defined by combinations of these markers.

\section{Conclusions}

In conclusion, we have demonstrated that Exhaustive Expansion is a valuable technique for analyzing higher order polychromatic FCM data sets. Exhaustive Expansion consists of:

- generating data for all possible 0- to N-parameter sets;

- creating appropriate data visualizations;

- identifying numerically interesting sets, using such metrics as CVs and p-values; and

- inspecting the numerically interesting sets for correlative analysis of clinically or biologically meaningful results.

This approach allows us to screen hundreds to thousands of phenotypes for biological responses. Use of free, widely available, and mature software components gives us the flexibility to pursue the data analysis in directions indicated by the data itself and the associated science. Our techniques are straightforward, yet highlight intriguing results when executed exhaustively across the entire data space. They support inductive reasoning by highlighting all cell subpopulations that meet appropriate numerical criteria. In both studies discussed here, our analysis provided the foundation for a refined understanding of complex phenotypes, and allowed for the development of new hypotheses pertaining to the identification and recovery of potentially important myogenic MSC progenitor cells, and tumor antigen-specific $\mathrm{CD}^{+} \mathrm{T}_{\mathrm{CM}}$ and $\mathrm{T}_{\mathrm{CM}}$ precursor populations for future clinical studies.

\section{Acknowledgements \\ Funding support was received from NIH (1R21-CS82614-01 and RA21- CA099265-02), the M. J. Murdock Charitable Trust, and the Chiles Foundations.}

\section{Author details}

${ }^{1}$ CytoAnalytics, Denver, CO, USA. ${ }^{2}$ Oregon Medical Laser Center, Providence St. Vincent Medical Center, Portland, OR, USA. ${ }^{3}$ Robert W Franz Cancer Research Center, Earle A. Chiles Research Institute, Providence Cancer Center, Portland, OR, USA.

\section{Authors' contributions}

KWG and EBW designed the research. LW, DPH, and AR performed the research. JCS and WM contributed vital analytical tools. JCS, LW, AR, BZ, and EBW analyzed and interpreted the data. JCS and EBW wrote the manuscript. All authors have read and approved the final manuscript.

\section{Competing interests}

JCS is Founder and President of CytoAnalytics. WM is Chief Technology Officer of CytoAnalytics.

Received: 29 April 2010 Accepted: 30 October 2010

Published: 30 October 2010

\section{References}

1. Perfetto SP, Chattopadhyay PK, Roederer M: Seventeen-colour flow cytometry: unravelling the immune system. Nat Rev Immunol 2004, 4:648-655

2. Pyne S, Hu X, Wang K, Rossin E, Lin T, Maier LM, Baecher-Allan C, McLachlan GJ, Tamayo P, Hafler DA, De Jager PL, Mesirov JP: Automated high-dimensional flow cytometric data analysis. Proc Natl Acad Sci USA 2009, 106:8519-8524.

3. Lo K, Brinkman RR, Gottardo R: Automated gating of flow cytometry data via robust model-based clustering. Cytometry A 2008, 73:321-332.

4. Murphy RF: Automated identification of subpopulations in flow cytometric list mode data using cluster analysis. Cytometry 1985, 6:302-309

5. Marincola FM: In support of descriptive studies; relevance to translational research. J Transl Med 2007, 5:21.

6. Valet G: Cytomics as a new potential for drug discovery. Drug Discov Today 2006, 11:785-791.

7. Valet $\mathrm{G}$, Leary JF, Tárnok A: Cytomics-new technologies: towards a human cytome project. Cytometry A 2004, 59:167-171.

8. Walker EB, Haley D, Petrausch U, Floyd K, Miller W, Sanjuan N, Alvord G, Fox BA, Urba WJ: Phenotype and functional characterization of long-term gp100-specific memory CD8+ T cells in disease-free melanoma patients before and after boosting immunization. Clin Cancer Res 2008, 14:5270-5283.

9. Gattinoni L, Zhong X, Palmer DC, Ji Y, Hinrichs CS, Yu Z, Wrzesinski C, Boni A, Cassard L, Garvin LM, Paulos CM, Muranski P, Restifo NP: Wnt signaling arrests effector $\mathrm{T}$ cell differentiation and generates CD8+ memory stem cells. Nat Med 2009, 15:808-813.

10. Berger C, Jensen MC, Lansdorp PM, Gough M, Elliott C, Riddell SR: Adoptive transfer of effector CD8+ T cells derived from central memory cells establishes persistent T cell memory in primates. J Clin Invest 2008, 118:294-305.

11. Gattinoni L, Powell DJ, Rosenberg SA, Restifo NP: Adoptive immunotherapy for cancer: building on success. Nat Rev Immunol 2006, 6:383-393.

12. Hassan HT, El-Sheemy M: Adult bone-marrow stem cells and their potential in medicine. J R Soc Med 2004, 97:465-471.

13. Gourgiotis S, Villias C, Germanos S, Foukas A, Ridolfini MP: Acute limb compartment syndrome: a review. J Surg Educ 2007, 64:178-186.

14. Ferrari G, Cusella-De Angelis G, Coletta M, Paolucci E, Stornaiuolo A, Cossu G, Mavilio F: Muscle regeneration by bone marrow-derived myogenic progenitors. Science 1998, 279:1528-1530.

15. Fukada S, Miyagoe-Suzuki Y, Tsukihara H, Yuasa K, Higuchi S, Ono S, Tsujikawa K, Takeda S, Yamamoto H: Muscle regeneration by reconstitution with bone marrow or fetal liver cells from green fluorescent protein-gene transgenic mice. J Cell Sci 2002, 115:1285-1293.

16. Corbel SY, Lee A, Yi L, Duenas J, Brazelton TR, Blau HM, Rossi FMV: Contribution of hematopoietic stem cells to skeletal muscle. Nat Med 2003, 9:1528-1532

17. Umemura T, Nishioka K, Igarashi A, Kato Y, Ochi M, Chayama K, Yoshizumi M, Higashi Y: Autologous bone marrow mononuclear cell implantation induces angiogenesis and bone regeneration in a patient with compartment syndrome. Circ J 2006, 70:1362-1364.

18. Tateishi-Yuyama E, Matsubara H, Murohara T, Ikeda U, Shintani S, Masaki H, Amano K, Kishimoto Y, Yoshimoto K, Akashi H, Shimada K, Iwasaka T, Imaizumi T: Therapeutic angiogenesis for patients with limb ischaemia by autologous transplantation of bone-marrow cells: a pilot study and a randomised controlled trial. Lancet 2002, 360:427-435. 
19. Herrera MB, Bruno S, Buttiglieri S, Tetta C, Gatti S, Deregibus MC, Bussolati B, Camussi G: Isolation and characterization of a stem cell population from adult human liver. Stem Cells 2006, 24:2840-2850.

20. Dicker A, Le Blanc K, Aström G, van Harmelen V, Götherström C Blomqvist L, Arner P, Rydén M: Functional studies of mesenchymal stem cells derived from adult human adipose tissue. Exp Cell Res 2005, 308:283-290.

21. Wilson A, Oser GM, Jaworski M, Blanco-Bose WE, Laurenti E, Adolphe C, Essers MA, Macdonald HR, Trumpp A: Dormant and self-renewing hematopoietic stem cells and their niches. Ann N Y Acad Sci 2007, 1106:64-75.

22. Pitchford SC, Furze RC, Jones CP, Wengner AM, Rankin SM: Differential mobilization of subsets of progenitor cells from the bone marrow. Cell Stem Cell 2009, 4:62-72.

23. Miller RJ, Banisadr G, Bhattacharyya BJ: CXCR4 signaling in the regulation of stem cell migration and development. J Neuroimmunol 2008, 198:31-38.

24. Zheng B, Cao B, Crisan M, Sun B, Li G, Logar A, Yap S, Pollett JB, Drowley L, Cassino T, Gharaibeh B, Deasy BM, Huard J, Péault B: Prospective identification of myogenic endothelial cells in human skeletal muscle. Nat Biotechnol 2007, 25:1025-1034.

25. Cerletti M, Jurga S, Witczak CA, Hirshman MF, Shadrach JL, Goodyear L, Wagers AJ: Highly efficient, functional engraftment of skeletal muscle stem cells in dystrophic muscles. Cell 2008, 134:37-47.

26. Crisan M, Yap S, Casteilla L, Chen C, Corselli M, Park TS, Andriolo G, Sun B, Zheng B, Zhang L, Norotte C, Teng P, Traas J, Schugar R, Deasy BM, Badylak S, Buhring H, Giacobino J, Lazzari L, Huard J, Péault B: A perivascular origin for mesenchymal stem cells in multiple human organs. Cell Stem Cell 2008, 3:301-313.

27. Middleton J, Americh L, Gayon R, Julien D, Mansat M, Mansat P, Anract $P$, Cantagrel A, Cattan P, Reimund J, Aguilar L, Amalric F, Girard J: A comparative study of endothelial cell markers expressed in chronically inflamed human tissues: MECA-79, Duffy antigen receptor for chemokines, von Willebrand factor, CD31, CD34, CD105 and CD146. J Pathol 2005, 206:260-268.

28. Ingram DA, Mead LE, Tanaka H, Meade V, Fenoglio A, Mortell K, Pollok K, Ferkowicz MJ, Gilley D, Yoder MC: Identification of a novel hierarchy of endothelial progenitor cells using human peripheral and umbilical cord blood. Blood 2004, 104:2752-2760.

29. Garlanda C, Dejana E: Heterogeneity of endothelial cells. Specific markers. Arterioscler Thromb Vasc Biol 1997, 17:1193-1202.

30. Lugli E, Pinti M, Nasi M, Troiano L, Ferraresi R, Mussi C, Salvioli G, Patsekin V, Robinson JP, Durante C, Cocchi M, Cossarizza A: Subject classification obtained by cluster analysis and principal component analysis applied to flow cytometric data. Cytometry A 2007, 71:334-344.

31. Casazza JP, Betts MR, Price DA, Precopio ML, Ruff LE, Brenchley JM, Hill BJ, Roederer M, Douek DC, Koup RA: Acquisition of direct antiviral effector functions by CMV-specific CD4+ T lymphocytes with cellular maturation. J Exp Med 2006, 203:2865-2877.

32. Betts MR, Nason MC, West SM, De Rosa SC, Migueles SA, Abraham J, Lederman MM, Benito JM, Goepfert PA, Connors M, Roederer M, Koup RA: HIV nonprogressors preferentially maintain highly functional HIV-specific CD8+ T cells. Blood 2006, 107:4781-4789.

33. Smith JW, Walker EB, Fox BA, Haley D, Wisner KP, Doran T, Fisher B, Justice L, Wood W, Vetto J, Maecker H, Dols A, Meijer S, Hu H, Romero P, Alvord WG, Urba WJ: Adjuvant Immunization of HLA-A2-Positive Melanoma Patients With a Modified gp100 Peptide Induces PeptideSpecific CD8+ T-Cell Responses. J Clin Oncol 2003, 21:1562-1573.

34. Swindle MM: Swine in the laboratory CRC Press; 2007.

35. Romero P, Zippelius A, Kurth I, Pittet MJ, Touvrey C, lancu EM, Corthesy P, Devevre E, Speiser DE, Rufer N: Four functionally distinct populations of human effector-memory CD8+ T lymphocytes. J Immunol 2007, 178:4112-4119.

36. Takata $\mathrm{H}$, Takiguchi M: Three memory subsets of human CD8+ T cells differently expressing three cytolytic effector molecules. I Immunol 2006, 177:4330-4340.

37. Perez AL, Bachrach E, Illigens BMW, Jun SJ, Bagden E, Steffen L, Flint A, McGowan FX, Del Nido P, Montecino-Rodriguez E, Tidball JG, Kunkel LM: CXCR4 enhances engraftment of muscle progenitor cells. Muscle Nerve 2009, 40:562-572.
38. Palmer DC, Restifo NP: Suppressors of cytokine signaling (SOCS) in T cell differentiation, maturation, and function. Trends Immunol 2009, 30:592-602.

39. Geginat J, Sallusto F, Lanzavecchia A: Cytokine-driven proliferation and differentiation of human naive, central memory, and effector memory CD4(+) T cells. J Exp Med 2001, 194:1711-1719.

40. Klebanoff CA, Gattinoni L, Torabi-Parizi P, Kerstann K, Cardones AR, Finkelstein SE, Palmer DC, Antony PA, Hwang ST, Rosenberg SA, Waldmann TA, Restifo NP: Central memory self/tumor-reactive CD8+ T cells confer superior antitumor immunity compared with effector memory T cells. Proc Natl Acad Sci USA 2005, 102:9571-9576.

41. da Silva Meirelles L, Chagastelles PC, Nardi NB: Mesenchymal stem cells reside in virtually all post-natal organs and tissues. J Cell Sci 2006, 119:2204-2213.

42. Sherwood Rl, Christensen IL, Conboy IM, Conboy MJ, Rando TA, Weissman IL, Wagers AJ: Isolation of adult mouse myogenic progenitors: functional heterogeneity of cells within and engrafting skeletal muscle. Cell 2004, 119:543-554.

43. Zuk PA, Zhu M, Ashjian P, De Ugarte DA, Huang Jl, Mizuno H, Alfonso ZC, Fraser JK, Benhaim P, Hedrick MH: Human adipose tissue is a source of multipotent stem cells. Mol Biol Cell 2002, 13:4279-4295.

44. Uezumi A, Ojima K, Fukada S, Ikemoto M, Masuda S, Miyagoe-Suzuki Y, Takeda S: Functional heterogeneity of side population cells in skeletal muscle. Biochem Biophys Res Commun 2006, 341:864-873.

45. Illa I, Leon-Monzon M, Dalakas MC: Regenerating and denervated human muscle fibers and satellite cells express neural cell adhesion molecule recognized by monoclonal antibodies to natural killer cells. Ann Neurol 1992, 31:46-52.

46. Precopio ML, Betts MR, Parrino J, Price DA, Gostick E, Ambrozak DR, Asher TE, Douek DC, Harari A, Pantaleo G, Bailer R, Graham BS, Roederer M, Koup RA: Immunization with vaccinia virus induces polyfunctional and phenotypically distinctive CD8(+) T cell responses. J Exp Med 2007, 204:1405-1416.

doi:10.1186/1479-5876-8-106

Cite this article as: Siebert et al.: Exhaustive expansion: A novel technique for analyzing complex data generated by higher-order polychromatic flow cytometry experiments. Journal of Translational Medicine 2010 8:106.

\section{Submit your next manuscript to BioMed Central and take full advantage of:}

- Convenient online submission

- Thorough peer review

- No space constraints or color figure charges

- Immediate publication on acceptance

- Inclusion in PubMed, CAS, Scopus and Google Scholar

- Research which is freely available for redistribution

Submit your manuscript at www.biomedcentral.com/submit
C Biomed Central 